\title{
Application of Arima Models in Millet Production in Andhra Pradesh
}

\author{
Shaik Nafeez Umar ${ }^{1 *}$, T. Gangaram², O. Hari Babu ${ }^{3}$, G. Sathyanarayana Reddy ${ }^{4}$, \\ B. Ramana Murthy ${ }^{1}$ and P. Samreen Aalia ${ }^{5}$
}

${ }^{1}$ Department of Statistics and Computer Applications, S V Agricultural College, Andhra Pradesh, India

${ }^{2}$ Department of Statistics, PVKN College, Andhra Pradesh, India

${ }^{3}$ Spirits College of MCA \& MBA, Andhra Pradesh, India

${ }^{4}$ Government College for Men (Autonomous), Andhra Pradesh, India

${ }^{5}$ Sree Rama Engineering College, Andhra Pradesh, India

*Corresponding author

\section{Keywords \\ Millet production, ARIMA, Theils U statistic \\ Article Info \\ Accepted: \\ 20 June 2021 \\ Available Online: \\ 10 July 2021}

\section{A B S T R A C T}

The study was intended to check and identify the best prediction model of Millet production in Andhra Pradesh through Auto Regressive Integrated Moving Average (ARIMA).Time series data on production of Millet for a period of 56 years (1963-2019) was used. The ARIMA (l 111$)$ model was identified as the appropriate procedure for the Millet production up to 2024. It was observed that there was a growing production.

\section{Introduction}

Millet locally known as "Bajra (Pearl millet)" is a nutritious course grain cereal. Worldwide, it is grown on an area of 34.6 million ha with annual production of 28.8 million tons (FAO, 2005). Millet is grown as food and fodder in arid and semi arid tropical environments. It is an important source of fodder in many countries of the world (Bhatnagar et al., 1998). It has high dietary value as nourish for poultry and livestock. Its cultivation in crop rotation has been shown to reduce nematode problems in wheat, soybean and potato. Millet is considered as the fifth important cereal crop, and most important millet (constitutes more than $55 \%$ of global millet production) and is grown in over 40 countries, predominantly in Africa and the Indian subcontinent.

Ahmad et al., (2005) attempted ARIMA models to forecast growth trends of production and export of Kinnow from Pakistan up to 2023 and concluded that there will be increase in trend in the coming years

Iqbal et al., (2005) forecasted the wheat area and production in Pakistan up to 2022 and found that the cropped area and output would 
increase in future, if the soil conservation and reclamation measures are adopted.

Goldsmith and Masuda (2009) used timeseries models to forecast world soybean production and harvested area up to 2030 by developing ARIMA models and found that world soybean production is predicted to increase about $2.2 \%$ annually.

Badmus et al., (2011) attempted Nigeria Maize production and harvested Area and concluded that production and harvested Area will expect to increase in next year's using ARIMA models. The purpose of the this study is to forecast millet production, using time series AARIMA models

\section{Materials and Methods}

The time series data were obtained from Directorate of Economics and Statistics, Andhra Pradesh.

Of the Time series data on production of Millet for a period of 56 years (1963-2019) was used for the model. The time series models were applied on the data.

In this study Box and Jenkin's methodology ARIMA model was used and predict upcoming millet production in Andhra Pradesh. Used various ARIMA models and identify the best appropriate fitting model. For this study, normality test, detection of outlier and residual analysis were used for process of building the time series models. The Statistical software Minitab and Gretl is used for modeling and predicting millet production time series of Andhra Pradesh.

\section{Shapiro-Wilks Normality test}

Normality of the data is one of the important assumption on the time series. The null hypothesis is the data belongs to normal.

$$
\mathrm{W}=\frac{\left(\sum_{t=2}^{n} a_{t} y_{t}\right)^{2}}{\sum_{t=1}^{n}\left(x_{t}-\bar{y}\right)^{2}}
$$

Where, $\mathrm{n}=$ number of observation, $\mathrm{y}_{\mathrm{t}}$ values of order sample and $a_{t}$ is tabulated coefficients.

\section{Box-Jenkins Methodology}

In an Auto Regressive Integrated Moving Average (ARIMA) the future value of a time series assumed to be a linearly and past observations are random errors. The time series has the form

$\mathrm{Y}_{\mathrm{t}}=\theta_{1} \mathrm{Y}_{\mathrm{t}-1}+\theta_{2} \mathrm{Y}_{\mathrm{t}-2}+\cdots+\theta_{\mathrm{p}} \mathrm{Y}_{\mathrm{t}-\mathrm{p}}-\emptyset_{1} \epsilon_{\mathrm{t}-1}-$ $\emptyset_{2} \epsilon_{\mathrm{t}-2} \ldots-\emptyset_{\mathrm{q}} \epsilon_{\mathrm{t}-\mathrm{q}}+\epsilon_{\mathrm{t}}$

$\mathrm{Y}_{t}$ is the time series, $\mathrm{p}$ is number of autoregressive parameters, qis number of moving averages. The Box-Jenkins (1970) methodologies were applied forecasting model. For this study, Millett production be a discrete time series variables which takes different variables over a period of time.

\section{Augmented-Dickey Fuller (ADF) test}

The unit root test is carried out the by using the Augmented-Dickey Fuller test. The hypothesis of ADF test was time series is stationary and alternative hypothesis is non stationary.

$\Delta \lambda_{t}=\alpha_{0}+\alpha_{2} t+\beta \Delta \lambda_{t-1} k_{i-1}+\varepsilon_{t}$

Where $\lambda t$ indicates the yearly millet production at time $\mathrm{t}, \beta$ is the coefficient to be estimated; $\mathrm{k}$ is number of lagged terms, $\alpha_{2}$ is estimated coefficient for the trend, $\alpha_{0}$ is the constant and $\varepsilon$ is error term

\section{Mean Absolute Percentage Error (MAPE)}

The average of absolute percentage amount by which forecasts differ from outcomes, used 
residual analysis for model forecasting. For evaluating the performance of forecasted model

MAPE has been applied, which is defines as

$$
\text { MAPE }=\frac{1}{n} \sum_{t=1}^{n} \frac{\left|a_{t}-f_{t}\right|}{a_{t}} * 100
$$

Where, $a_{t}$ is Actual data and $f_{t}$ is Forecasted data with respective time period $t$

\section{Theil's U Statistic}

Model forecast accuracy is plays important role for forecasting of upcoming values. Theil's U test gives us accuracy of the model, $\mathrm{U}$ lies between 0 and 1 , with values closer to 0 indicates greater forecasting model.

$$
U=\frac{\sqrt{\sum_{t=1}^{n}\left(a_{t}+f_{t}\right)^{2}}}{\sqrt{\sum_{t=1}^{n} a_{t^{2}}}+\sqrt{\sum_{t=1}^{n} f_{t^{2}}}}
$$

Where, $a_{t}$ is actual values of time series and $f_{t}$ is forecasted values

\section{Results and Discussion}

For this study, Shapiro -Wilk's test was used for normality of time series data, the test pvalue is 0.1091 which is highly significant at 0.01 level, the null hypothesis is a sample belongs to a normal distribution the study shows distribution of the data are not significantly different from normal distribution. The study here employs the unit root test to examine the time series data is stationary or not. For the test of ADF test was -15.244 , which is significantly at 0.05 levels, reject null hypothesis and considered as the time series data has stationary, which means the time series data follows stationary at first difference.(Table 1).

The suitable ARIMA model concerned with examination of residual of the model in systematic way, which is helpful for improve the time series ARIMA model.

The Auto Correlation Function (ACF) and Partial Auto Correlation Function (PACF) were used for order of ARIMA model, It is helpful for time series data has been stationaries by differencing (Figure:1 and 2).

The appropriate models were identified through the procedure of Box-Jenkins's methodology (ARIMA).

From the various forms of following ARIMA (p d q) models viz ARIMA (1 0 1); ARIMA (1 1 1), ARIMA ( $\left.\begin{array}{lll}0 & 1 & 1\end{array}\right)$, ARIMA (l 110$)$ and ARIMA (1 00 ); the best model was chosen on the basis of high coefficient of determination, low Mean Absolute Percentage Error (MAPE) and lesser Theil U-Statistics.

Among the comparison of ARIMA models,

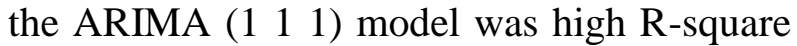
value 0.710 which significantly at 0.01 level and MAPE is 14.798 and their Theil's Statistic is 0.698 , it indicates better accuracy forecasting model comparing other ARIMA models (Table 2). The output has shown between 1963 and 2019 millet production is of yearly increasing. In view of residual analysis for ARIMA ( $\left.\begin{array}{lll}1 & 1 & 1\end{array}\right)$ being an evidence of normality, all the points close to the line, it indicates the model would be good for prediction (Figure 1). In the forecasting of millet production, in the year 2024 highest production 
Table.1 Diagnosis of the Model

\begin{tabular}{|c|c|c|}
\hline Diagnosis test & Value & p-value \\
\hline Shapiro-Wilk's Normality test & 0.943 & $0.1091(\mathrm{p}>0.01)$ \\
\hline Augmented-Dickey Fuller test (Stationary) & -15.244 & $0.0282(\mathrm{p}<0.05)$ \\
\hline
\end{tabular}

Table.2 Represents ARIMA models of Millet production Yield (Kg./Hectare)

\begin{tabular}{|c|c|c|c|}
\hline ARIMA Model & R-Square & MAPE & Theil's-U Statistic \\
\hline ARIMA (1 0 1) & $0.637^{* *}$ & 15.863 & 0.769 \\
\hline ARIMA (1 1 1 1) & $0.710^{* *}$ & 14.798 & 0.698 \\
\hline ARIMA ( $\left.\begin{array}{lll}0 & 1 & 1\end{array}\right)$ & $0.695^{* *}$ & 15.036 & 0.712 \\
\hline ARIMA (1 1 1 0) & $0.656^{* *}$ & 15.187 & 0.777 \\
\hline ARIMA (1 0 0) & $0.682^{* *}$ & 18.221 & 0.912 \\
\hline
\end{tabular}

Note: ** Significant at 0.01 levels

Table.3 Forecasting model for millet production time series in Andhra Pradesh (Kg./Hectare)

\begin{tabular}{|c|c|c|c|}
\hline \multicolumn{4}{|c|}{ ARIMA ( 1 1 1) } \\
\hline Year & Forecast & UCL (95\% CL) & LCL (95\%CL) \\
\hline $\mathbf{2 0 2 0}$ & 1233.58 & 1488.78 & 978.39 \\
\hline $\mathbf{2 0 2 1}$ & 1179.36 & 1434.98 & 923.74 \\
\hline $\mathbf{2 0 2 2}$ & 1217.19 & 1492.03 & 942.35 \\
\hline $\mathbf{2 0 2 3}$ & 1222.03 & 1505.66 & 938.40 \\
\hline $\mathbf{2 0 2 4}$ & 1238.69 & 1533.70 & 943.68 \\
\hline $\mathbf{2 0 2 5}$ & 1251.11 & 1556.05 & 946.17 \\
\hline
\end{tabular}

Fig.1 Auto Correlation coefficients of residuals of ARIMA (llll 11 ) model for the Millet Production

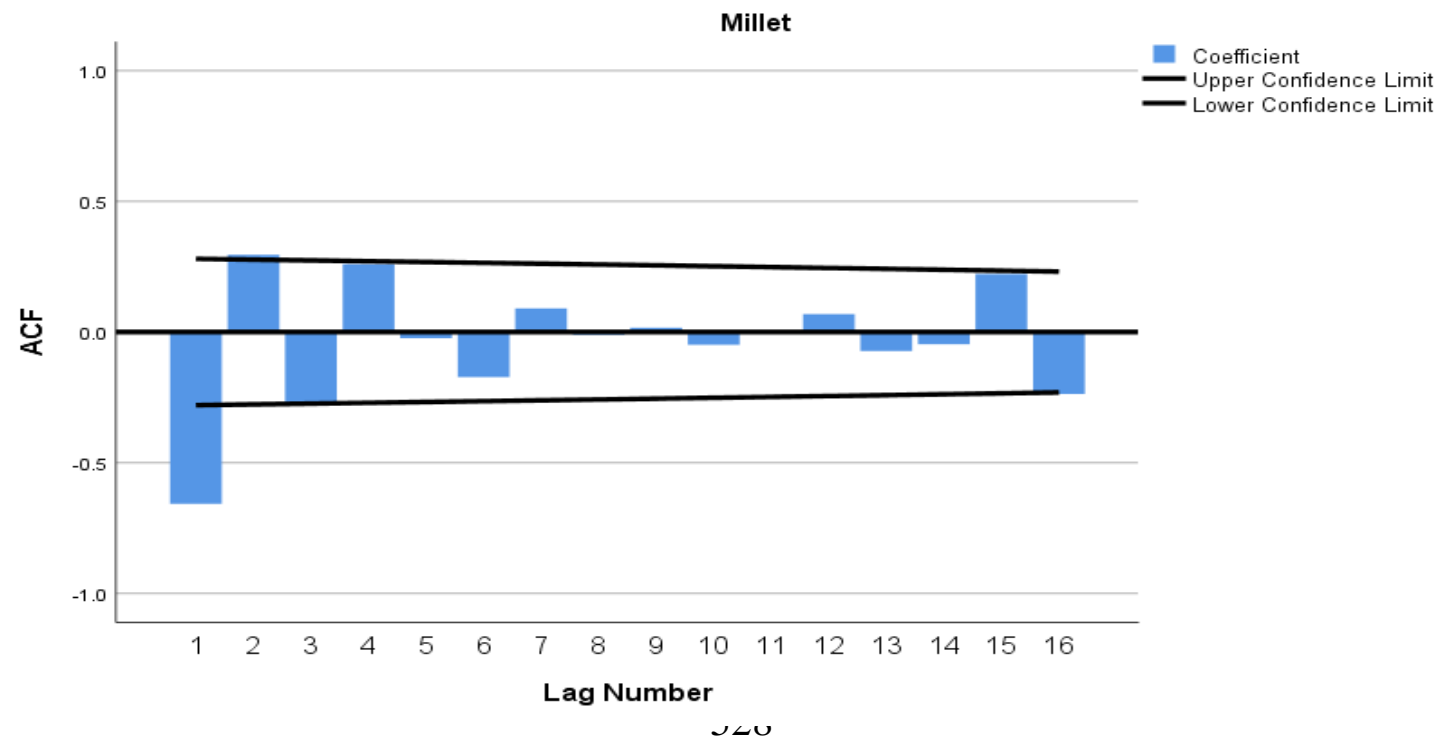


Fig.2 Partial Auto Correlation coefficients of residuals of ARIMA (llll 11 ) model for the Millet Production

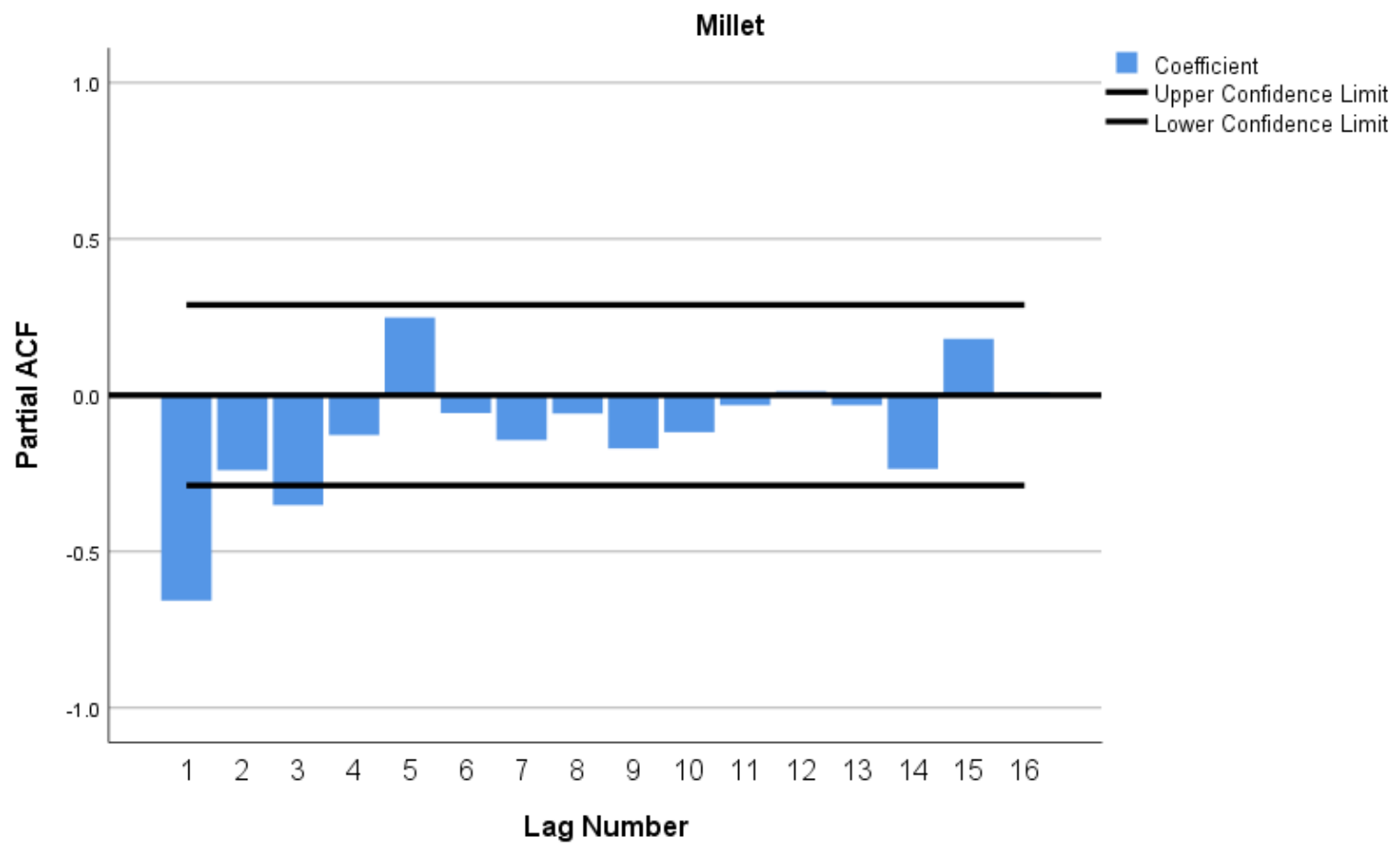

Fig.3 Residual analysis of Millet Production ARIMA (111)

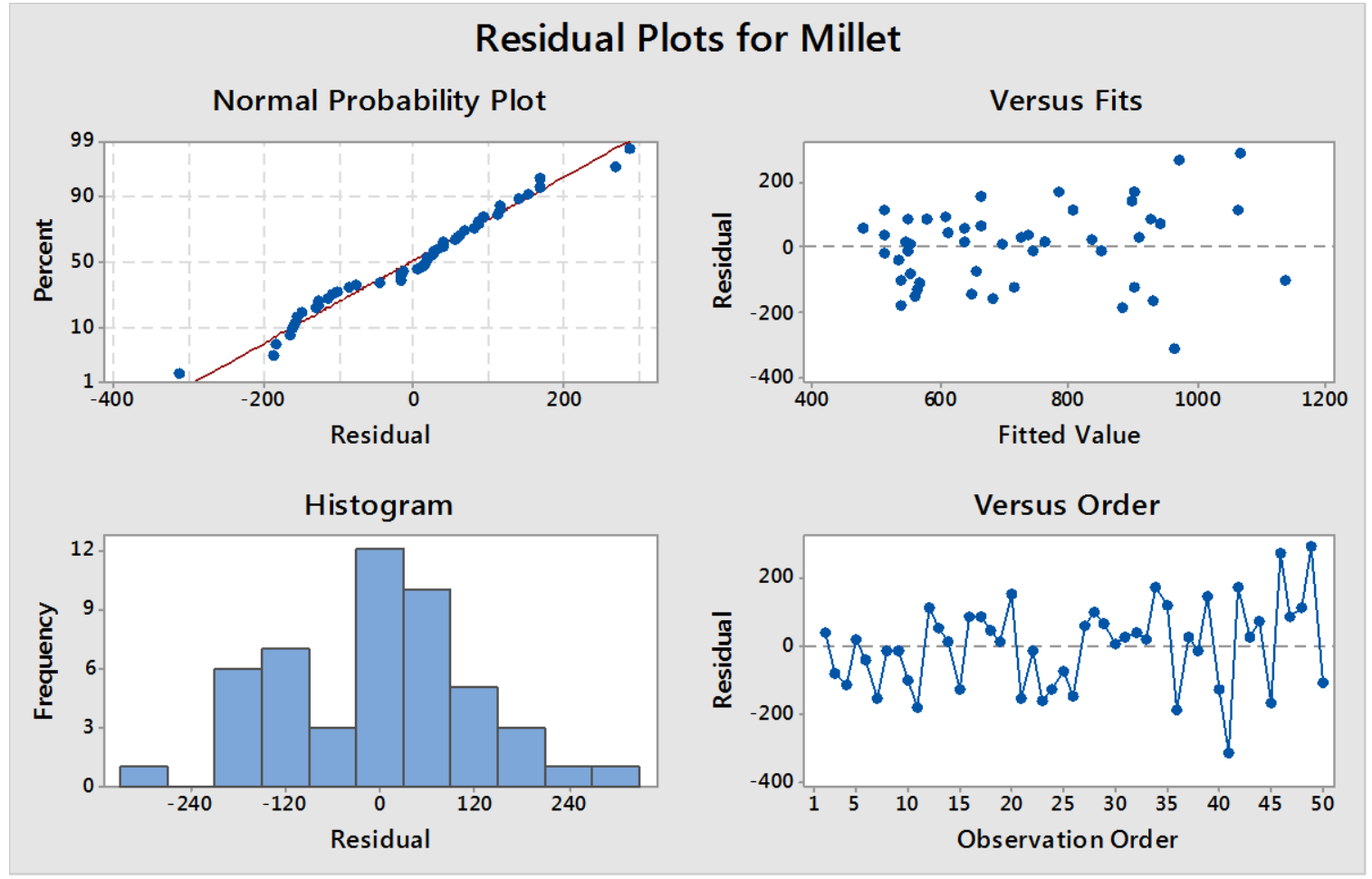


Fig.4 Actual and forecast of Millet production ARIMA (111)

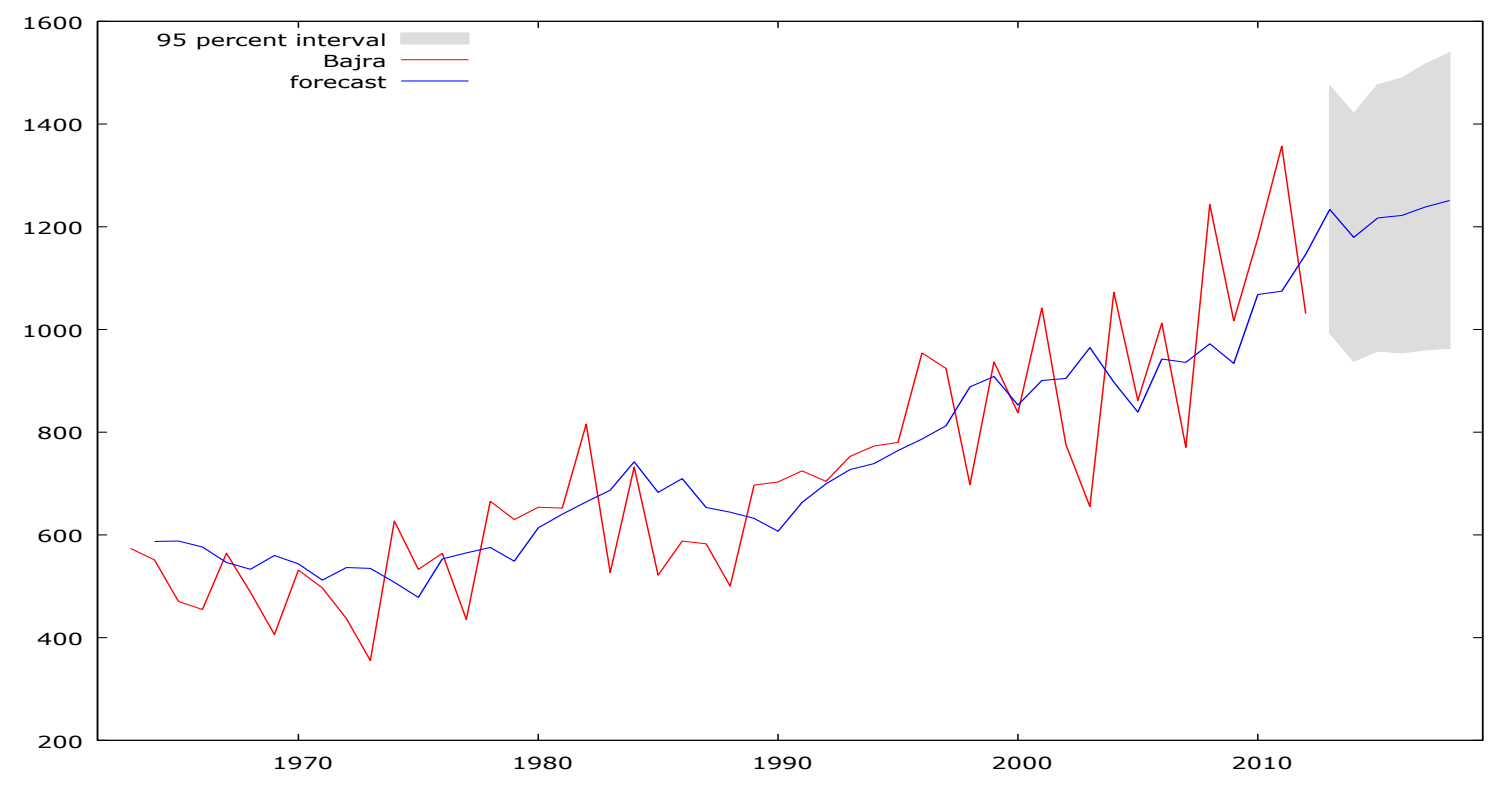

A time series model provides an appropriate techniques for predicting the data of any variable. The study urbanized production of millet model was exponential trend. Overall, the model can be seen that forecasted production of millet has increasing trend over the time period 1963 to 2019 respectively. The

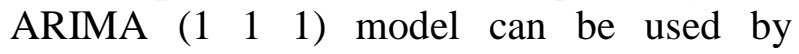
researchers for the predicting the millet in Andhra Pradesh. However, it should be updated from the over the time period and inclusion of existing data. The time series ARIMA model can be utilized with appropriate results in other traditional models concerning evolution of the production. The time series ARIMA model can be deployed for reaching dependable production forecast for many agricultural produce that have immense policy suggestions.

\section{References}

Directorate of Economics and Statistics www. http://eands.dacnet.nic.in/

Broken, V. K. 2000. Forecasting Spring Wheat Yield Using Time Series Analysis: A Case Study for the
Canadian Prairies, Agronomy Journal, 92(6):1047-1053.

Finger, R. 2007. Evidence of Slowing Yield Growth- The example of Swiss Cereal Yield. Agri-food and Agri environmental Economics Group, ETHZürich, Switzerland. Government of Pakistan. 2012. Economic survey of Pakistan, economic advisory wing, finance department, Islamabad.

Karim, R. Awala, A. and Akhter, M. 2010.Forecasting of wheat production in Bangladesh, Bangladesh J.Agril. Res.35(1):17-28.

Malleshi, N. G., and H. S. R. Desikachar. 1985. Miling, popping and malting characteristics of some minor Millets.J. Food Sci. 22:400.

Rimi, R. H. Rahman, S. H. Karmaker, S. and G. Hussain. 2011. Trend Analysis of Climate Change and Investigation on its Probable Impacts on Rice Production at Satkhira, Bangladesh, Pakistan Journal of Meteorology Vol.6.

Nusrat Habib, Muhammad Zubair, Ikram Saeed, 2013. Forecasting of Millet 
Area and Production in Pakistan, Journal of Social Welfare and Human Rights. Pp 47-52.

Hassan, Thabit Ahmed (2002) Instability of the main Food Grain (Millet and Sorghum) Production in the Sudan with Reference to South Darfur State, unpublished $\mathrm{PhD}$ Faculty of Agriculture, $\mathrm{U}$ of $\mathrm{K}$.

Box G E P, Jenkins G M (1970). Time Series Analysis, Forecasting and Control. Holden Day, San Francisco. pp.46-87.

Seydou Zakari and Liu Ying (2012) Forecasting of Niger Grain Production and Harvested Area, Asian Journal of Agricultural Sciences 4(4): 308-313, 2012, ISSN: 2041-3890

Ahmad, B., A. Ghafoor and H. Badar, 2005.
Forecasting and growth trends of production and export of kinnow from Pakistan. J. Agric. Soc. Sci., 1: 20-24.

Iqbal, N., K. Bakhsh, A. Makbool and A. S. Ahmad, 2005. Use of the ARIMA model for forecasting wheat area and production in Pakistan. J. Agric. Soc. Sci., 1(2): 120-122.

Goldsmith, P. D. and T. Masuda, 2009. World soybean production: Area harvested, yield and long-term projections. Int. Food Agribus. Manage. Rev., 12(4): 143-162.

Badmus, M. A. and O. S. Ariyo, 2011. Forecasting cultivated area and production of maize in Nigeria using ARIMA model. Asian J. Agric. Sci., 3(3): 171-176.

\section{How to cite this article:}

Shaik Nafeez Umar, T. Gangaram, O. Hari Babu, G. Sathyanarayana Reddy, B. Ramana Murthy and Samreen Aalia, P. 2021. Application of Arima Models in Millet Production in Andhra Pradesh. Int.J.Curr.Microbiol.App.Sci. 10(07): 525-531. doi: https://doi.org/10.20546/ijcmas.2021.1007.057 